Branch"C2020.

Available online

\title{
ROLE OF LASERS IN RECREATING SPEECH -A SPECIAL CASE OF ANKYLOGLOSSIA
}

Dr.Sathish kumar.K, Dr.Ramakrishnan.T*, Dr.Priyadurga.K, Dr.Ramnath.E, Dr. Mejalla. M.A, Dept. of Periodontology, Adhiparasakthi Dental College and Hospital, Melmaruvathur, Tamil Nadu, India.

*Principal, Faculty of Dentistry, Meenakshi Academy of Higher Education and Research, Maduravoyal, Chennai, Tamilnadu, India.

\section{To access $\&$ cite this article}

Website: jidam.idamadras.com

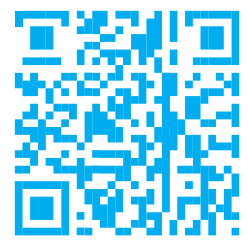

DOI:10.37841/jidam_2020_V7_I3_05

\section{Address for Correspondence:}

Dr.K.Sathish kumar

Post Graduate Student, Department of

Periodontology,

Adhiparasakthi Dental College and Hospital,

Melmaruvathur- 603 319. Tamil Nadu, India

Email id: sathishperio94@gmail.com

\section{ABSTRACT}

Ankyloglossia or tongue-tie is an inborn anomaly that causes restriction of tongue movements. It is characterized by the position of lingual frenum inbetween the tongue and the floor of the mouth. A 17-year-old female patient with the complaint of difficulty in speech was diagnosed with ankyloglossia. To restore her normal speech, laser frenectomy using a diode laser $(940 \mathrm{~nm})$ was the technique considered over the conventional method to remove the high frenal attachment and to avoid complications caused by the scalpel technique. Post-operative evaluation showed complete healing at the end of 2 to 6 weeks with an increase in tongue mobility of $\geq 15 \mathrm{~mm}$ after laser surgery. After treatment, the patient showed faster healing, early restoration of function and less post-operative pain; thus, proving to be more efficient than the conventional scalpel technique.

KEYWORDS: Ankyloglossia, LASER, Frenectomy.

$\begin{array}{ll}\text { Received } & : 01.06 .2020 \\ \text { Accepted } & : 16.08 .2020 \\ \text { Published } & : 27.09 .2020\end{array}$ 


\section{INTRODUCTION:}

Ankyloglossia, also well-known as tonguetie, is an inborn dental anomaly that may limit the motility of the tongue tip, and it is characterized by a short, dense lingual frenulum, a firm tissue joining the base of the tongue to the floor of the mouth ${ }^{1}$. Etymologically, "ankyloglossia" is derived from the Greek words "agkilos" (curved) and "glossa" (tongue). Wallace defined tongue-tie as "a state in which the tip of the tongue cannot be extended beyond the lower incisor teeth because of the small lingual frenum, often containing scar tissue" ${ }^{2}$. The lingual frenulum separates just before birth to allow motion of the tongue. In case of tongue-tie, the lingual frenulum remains attached to the base of the tongue. The exact cause is still unknown, although some cases of tongue-tie have been linked with certain genetic factors. Occasionally tongue-tie may not cause any complications. In some cases, this condition may require attention and needs to be treated to improve the patient's functional, physical and mental health. Surgical correction can be done conventionally or by using lasers. In this case, lingual frenectomy is done with a diode laser, which involves the removal of thick band of lingual frenum connecting the tongue to the floor of the mouth thereby increasing the tongue movement.

\section{CLINICAL PRESENTATION:}

A 17-year-old healthy female patient reported with the complaint of difficulty in speech articulation and brushing since childhood. Her intraoral examination revealed that there was complete ankyloglossia with less than $10 \mathrm{~mm}$ of tongue movement and was categorized as class II according to Kotlow's classification ${ }^{6}$ (Fig 2). Based on the above clinical findings, a diagnosis of ankyloglossia was made. As a part of treatment planning to eliminate the high frenal attachment, a frenectomy procedure was planned to eliminate the high frenal attachment. Patient was educated about the possible longstanding effects of tongue-tie for a better acceptance of treatment. Lingual frenectomy was planned by using soft tissue diode laser and written consent was obtained from the patient. In the above case, the use of laser was preferred over the surgical method because of minimal bleeding and post-operative complications as the patient was young. Diode laser (940nm) with $1.5 \mathrm{w}$ graded pulse mode was used. 
taking acidic liquids such as carbonated drinks for a few days and hard foods that may irritate the area. The patient was prescribed antibiotics, analgesics and warm saline rinses to facilitate faster healing. It was also explained that a small white patch, representing the healing tissue may develop at the exposed site which is a part of the normal healing process and not an infection.

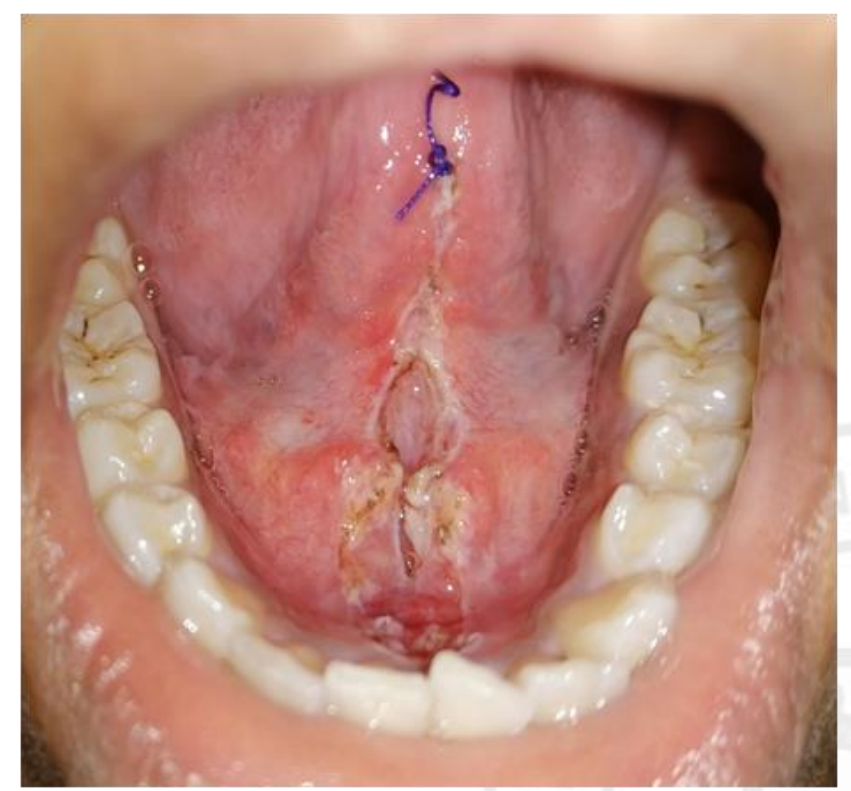

Fig 3 : Immediately After Laser Lingual Frenectomy - Front View

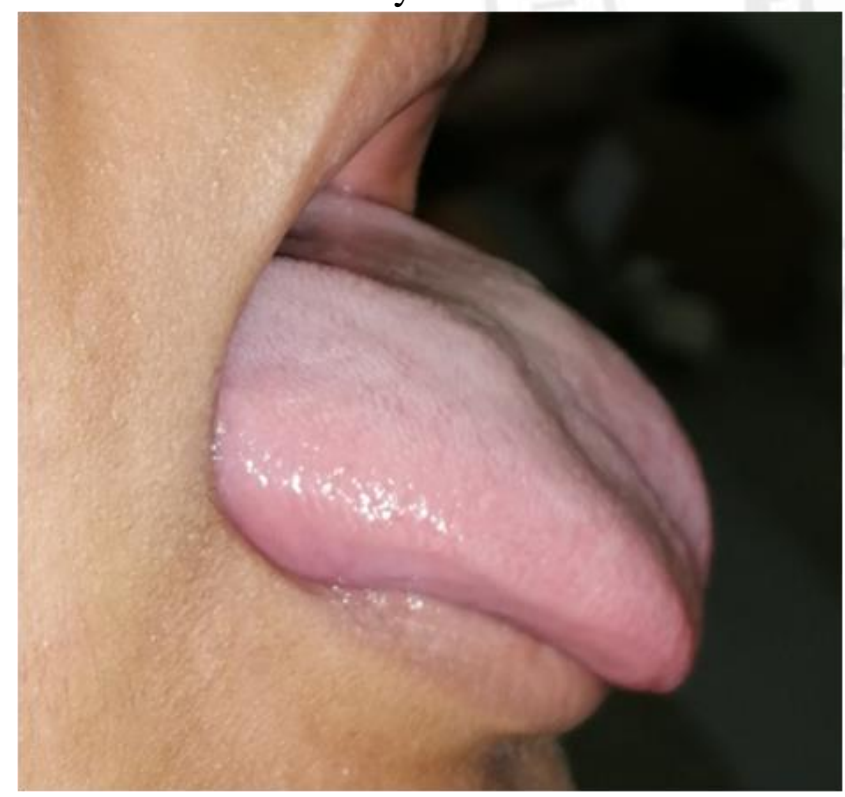

Fig 4: Immediately After Laser Lingual Frenectomy - Lateral View

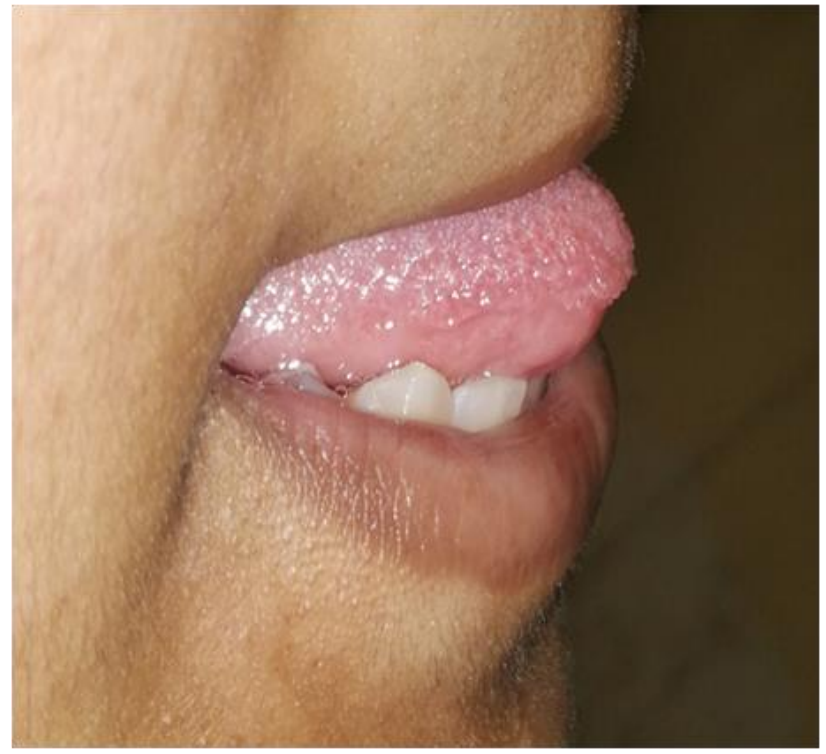

Fig 5 : Post-operative Image After One Week Lateral View

\section{CLINICAL OUTCOMES:}

The patient was evaluated after one week, the tissues showed uneventful healing with "white soft scab" formation (Fig 6) and complete healing had occurred at the end of 2 to 6 weeks with an increase in tongue movement of $\geq 15 \mathrm{~mm}$ after laser surgery (Fig 8). There was a 6-7 $\mathrm{mm}$ increase in the movement of the tongue after laser surgery. Speech pronunciation was markedly enhanced after the frenectomy procedure.

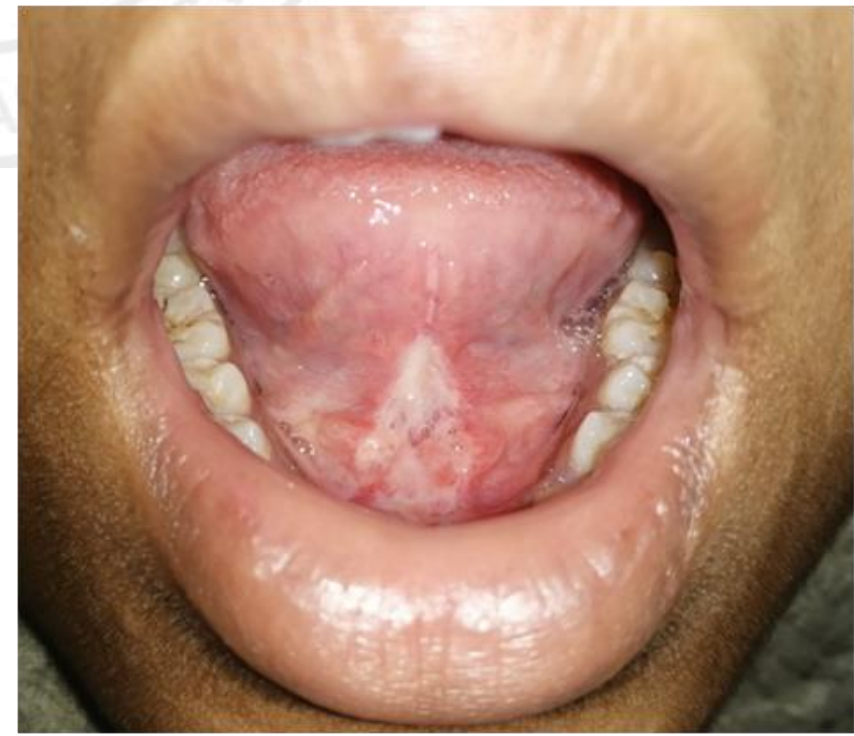

Fig 6: Post-operative Image After 1-Week Showing "White Soft Scab" Formation 


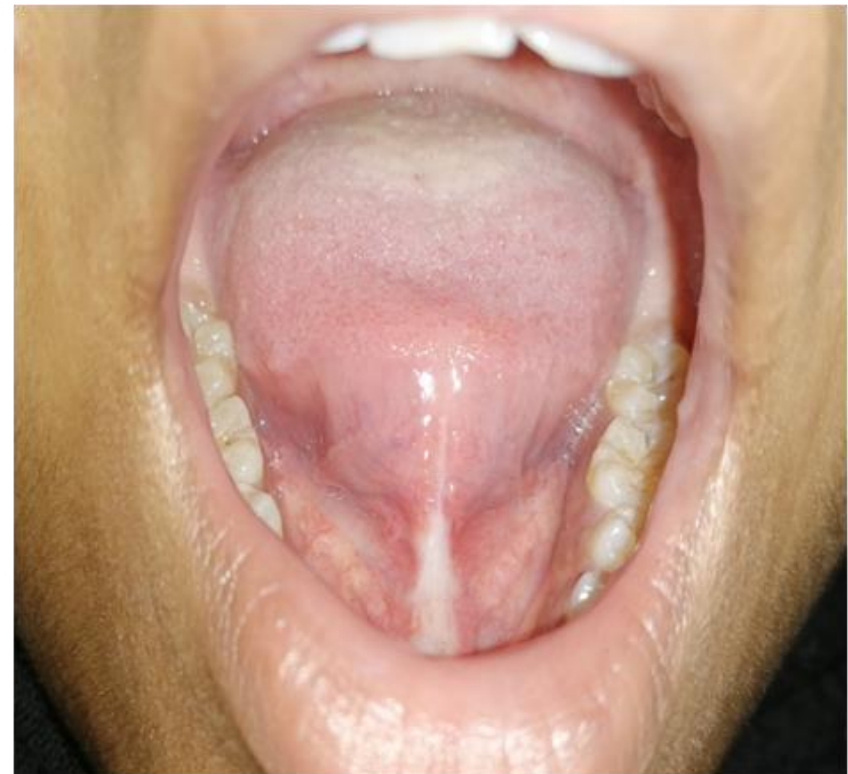

Fig 7: Post-Operative Image after One Month with Uneventful Healing

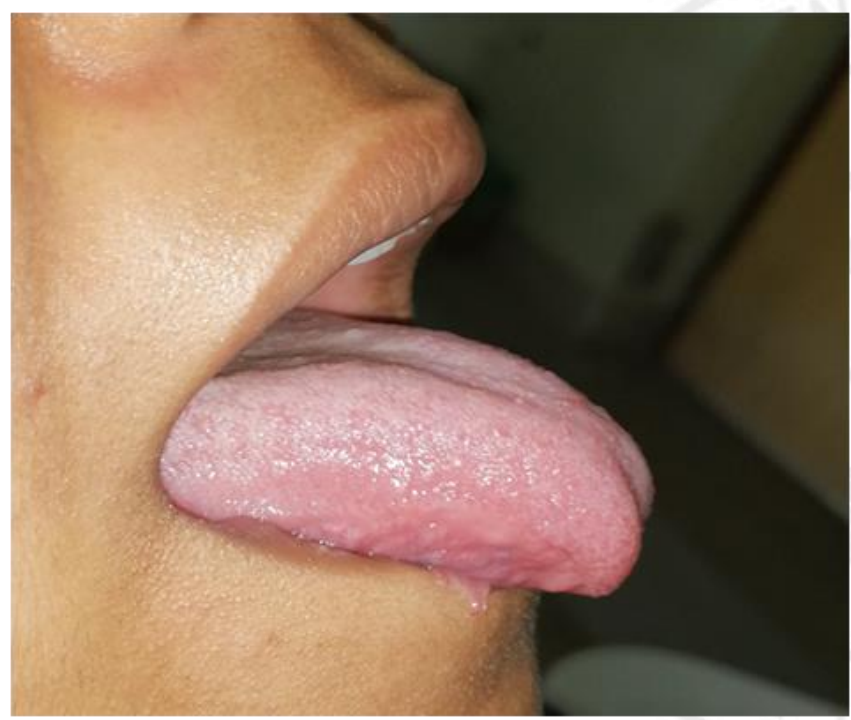

Fig 8 : Post-Operative Image After One Month Lateral View

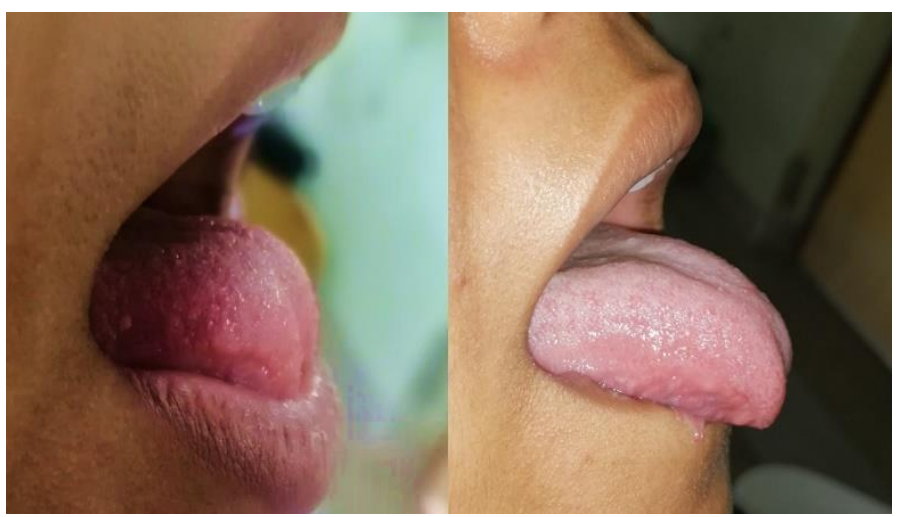

Fig 9 : Before And After Laser Frenectomy (Lateral View)

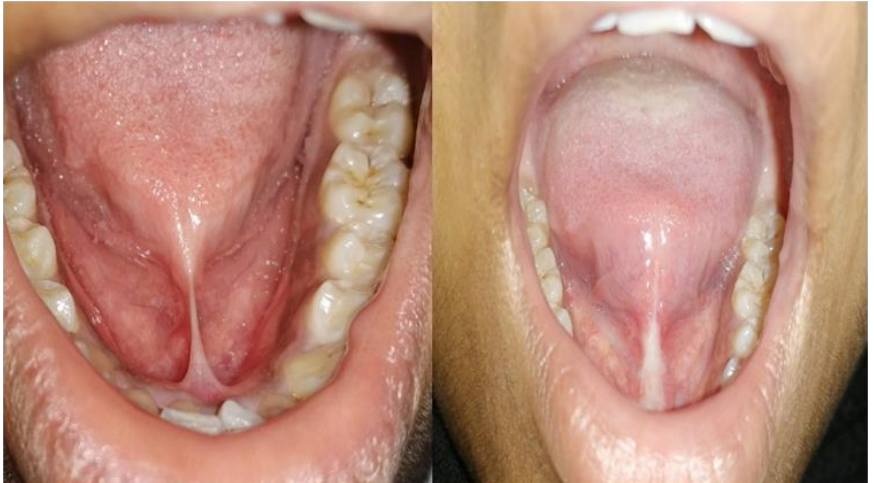

Fig 10 : Before and after Frenectomy ( Frontal View)

\section{DISCUSSION:}

A short dense lower lingual frenum ("tongue tie") attached to the tip of the tongue is known as ankyloglossia. It may be complete when the ventral surface is attached to the floor of the mouth or partial when the lingual frenum is shorter. Ankyloglossia occurs in about $1.7 \%$ of all neonates without any gender predilection and is reported to be transitory ${ }^{5}$.

Kotlow's 4 classes of ankyloglossia are based on the distance from frenum attachment to the tip of the tongue ${ }^{6}$. A distance of $16 \mathrm{~mm}$ is normal, while Classes 1 to 4 are associated with reduced distances and increasing severity of dysfunction: Class I $=12$ $16 \mathrm{~mm}$ (mild); Class II = 8-11 mm (moderate); Class $\mathrm{III}=3-7 \mathrm{~mm}$ (severe); Class IV = attached at the tip of the tongue (very severe) ${ }^{6}$.

Ankyloglossia can cause several problems such as difficulty in deglutition, speech articulation, malocclusion, and probable periodontal problems ${ }^{4}$. Hence, the management of ankyloglossia depends on the age of the patient and their history of speech articulation, breast-feeding, mechanical, or social complications. The various treatment options available are conventional surgical scalpel techniques (frenotomy, frenectomy, frenuloplasty), electrocautery, and lasers. Frenotomy is a simple incision of the frenulum. Frenectomy is defined as complete excision of the frenulum ${ }^{7}$. Difficulties after frenotomy, frenectomy, and frenuloplasty are uncommon. Disadvantages of conventional surgical frenectomies include increased blood loss, obstruction of Wharton's duct on suturing the ventral surface of tongue leading to retention cyst, injury to the lingual nerve, which causes loss of sensation on the tip of the tongue. 
Diode lasers have many benefits when compared to conventional scalpel surgeries. They are convenient and handy in design. They have effective and reliable advantages for use in various soft tissue oral surgical procedures. Frenectomies done with laser permit excision of the frenum painlessly, without blood loss, sutures, or surgical packing, and with excellent post-surgical healing of the tissue. Zeinoum et al reported that histologically, laser wounds contain a significantly lesser number of myofibroblasts, which leads to minimum wound contraction and scarring, and result in enhanced wound healing 8 .

\section{CONCLUSION:}

This case report enhances the use of lasers over the conventional scalpel technique for frenectomy which allows improved patient perception in terms of post-operative pain and function. This procedure also brings about the use of lasers in patients, where giving local anaesthesia is contraindicated.

\section{ACKNOWLEDGEMENT:}

I warmly acknowledge my past Professor and HOD, Dr.T.Ramakrishnan who is now the Principal of Meenakshi Ammal Dental College.

\section{FINANCIAL SUPPORT AND SPONSORSHIP:}

Nil

\section{CONFLICT OF INTEREST:}

There is no conflict of interest.

\section{REFERENCES:}

1. Reddy NR, Marudhappan Y, Devi R, Narang S. Clipping the (tongue) tie. J Ind Soc Periodontol 2014 May;18(3):395.

2 Wallace AF. Tongue tie. Lancet 1963; 2:3778 .

3. Ayer FJ, Hilton LM. Treatment of ankyloglossia: Report of a case. ASDC J Dent Child 1977; 44:69-71.

4. Hughes CL, Bass JW. The oral-facial-digital syndrome: Report of a case. Oral Surg Oral
Med Oral Pathol 1966;22:265-71.

5. Ballard JL, Auer CE, Khoury JC. Ankyloglossia: Assessment, incidence, and effect of frenuloplasty on the breastfeeding dyad. Pediatrics 2002;110:e63.

6. Kotlow LA. Ankyloglossia (tongue-tie): A diagnostic and treatment quandary. Quint Intl 1999;30:259-62.

7. Chaubal TV, Dixit MB. Ankyloglossia and its management. J Ind Soc Periodon. 2011 Jul;15(3):270.

8. Zeinoun T, Nammour S, Dourov N, Aftimos G, Luomanen M. Myofibroblasts in healing laser excision wounds. Lasers Surg Med 2001;28:74-9. 